\title{
Los docentes ante la integración educativa del teléfono móvil en el aula
}

\section{Tearchers at the educational integration of the mobile phone in the classroom}

\author{
Francisco Brazuelo Grund \\ UNED. Las Palmas de Gran Canaria, España \\ fbrazuelo@invi.uned.es \\ Domingo José Gallego Gil \\ Universidad Camilo José Cela, Madrid, España \\ dgallego@edu.uned.es \\ María Luz Cacheiro González \\ UNED, Madrid, España \\ mlcacheiro@edu.uned.es
}

\begin{abstract}
Resumen
Este artículo presenta una investigación sobre la integración del teléfono móvil por parte de los docentes de Educación Secundaria Obligatoria de Las Palmas (Islas Canarias, España) analizando su uso, actitudes y posibilidades. Se trata de un estudio exploratorio y descriptivo con un enfoque mixto (cuantitativo y cualitativo) para el que se ha aplicado un cuestionario de 11 dimensiones a una muestra de docentes $(n=223)$, realizando también entrevistas personales $(n=19)$. El análisis estadístico de los datos ha sido univariado y bivariado para obtener la máxima información del cruce de variables. Los resultados de la muestran un gran desconocimiento de los docentes en cuanto a los usos educativos del teléfono móvil como herramienta de enseñanza y aprendizaje (93,3\%). No obstante, un 56,5\% manifiesta interés en conocer cómo llevar a cabo su integración educativa en el aula, con mayor incidencia entre los docentes de menor edad (36-50 años), más flexibles y receptivos, coincidiendo en esta orientación, con otros estudios de incorporación escolar de las TIC para este nivel educativo.
\end{abstract}

Palabras clave: Teléfono móvil, Aprendizaje móvil, Docentes, Educación Secundaria

\begin{abstract}
This article presents a research on the integration of mobile phones by teachers of Secondary Education in Las Palmas (Canary Islands, Spain) analyzing their use, attitudes and possibilities. This is an exploratory and descriptive study with a mixed approach (quantitative and qualitative) in which a questionnaire of 11 dimensions has been applied to a sample of teachers $(n=223)$, also conducting personal interviews $(n=19)$. Statistical analysis of the data has been univariate and bivariate to obtain the maximum information of crossing variables. The results show a great lack of teachers regarding the educational uses of mobile phone as a tool for teaching and learning $(93,3 \%)$. However, $56,5 \%$ expressed interest in how to carry out their educational integration in the classroom, with the highest incidence among teachers of younger age (36-50 years), more flexible and responsive, coinciding in this orientation, with other studies about incorporation of ICT at school for this educational level.
\end{abstract}

Keywords: Mobile Phone, Mobile Learning, Teachers, Secondary Education 


\section{Introducción}

Se estima que en 2015 la cifra global de usuarios de internet ha alcanzado los 3,2 billones y más de 7 billones de teléfonos móviles (International Telecommunication Union, 2015). Esta difusión ha convertido este medio de comunicación en el más extendido superando a otros, tradicionales, digitales y analógicos, como la prensa escrita, la televisión e Internet (Attewell, Savil-Smith y Douch, 2009).

La tasa de penetración del teléfono móvil en España se sitúa en el 109\% (ONTSI, 2016). El teléfono móvil ha pasado de ser un dispositivo limitado a permitir y recibir llamadas, a un convertirse en un artefacto "inteligente" que posee múltiples opciones comunicativas, multimedia y ofimáticas: posibilidad de enviar mensajes SMS y MMS, hacer fotos, grabar audio y vídeo, almacenar datos, música y vídeo, orientarnos por GPS, crear y editar documentos y hojas de cálculo, conectarnos vía Wi-Fi, envío de mensajería instantánea a través de apps o la navegación por internet (Kadirire, 2007; Woodill, 2010; Dykes y Renfrew, 2012).

El teléfono móvil da paso al smartphone o teléfono móvil inteligente con sus nuevos sistemas operativos y la posibilidad de instalar aplicaciones de terceros o aplicaciones móviles (apps). Bates (2015) considera que el aprendizaje móvil permite que los estudiantes dediquen tiempo a crear artefactos, pudiendo mostrar su aprendizaje de formas concretas. Estas características junto a su facilidad de uso, portabilidad y ubicuidad, lo han convertido en el primer medio de comunicación universal de la historia (Corbell, 2007; Traxler, 2009; Sharples, 2010), trascendiendo edad, posición social o situación geográfica.

El estudio llevado a cabo por el Grupo de investigación GRIAL de la Universidad de Salamanca propone un modelo de aceptación de la tecnología móvil por parte de los profesores en el que se integran 8 constructos: percepción de utilidad, facilidad de uso percibida, la intención de conducta, la experiencia anterior, el disfrute percibido, autoeficacia, condiciones facilitadoras y norma subjetiva (Sánchez, Olmos y García, 2016).

Uno de los sectores sociales que ha tenido una mayor penetración del teléfono móvil es el de los jóvenes de edades entre 15 y 35 años. El 100\% disponen de teléfono móvil y, entre sus diversos usos, se sabe que, además, cada vez son más los que lo utilizan para acceder a internet. Según los datos publicados por el "Séptimo Observatorio de Tendencias Nokia", encargado por esta marca de telefonía móvil a la consultora de investigación social y de mercado Conecta (CONECTA, 2012), el porcentaje de personas comprendidas en esta franja de edad que se conectan a Internet desde un móvil alcanza al $64 \%$ de los encuestados. Este uso mayoritario de internet móvil responde a la necesidad de buscar información, enviar y recibir correos electrónicos y acceder a redes sociales. Además, el crecimiento de los smartphones, ha estimulado la descarga y ejecución de las apps y a un aumento creciente en el consumo de banda ancha móvil además de terminales con mayores velocidades, memoria de almacenamiento y disponibilidad de tiempo de acceso generalmente tarificado de forma mensual por las principales operadoras telefónicas en España.

$\overline{\text { Los docentes ante la integración educativa del teléfono móvil en el aula. Francisco Brazuelo, }}$ Domingo José Gallego y María Luz Cacheiro. 
No obstante, esta realidad social no tiene un reflejo en el contexto educativo. Si bien, sociedad y escuela deberían estar estrechamente unidas, existe una divergencia entre ambas. Y una de sus manifestaciones es la resistencia docente a la incorporación del teléfono móvil como una TIC educativa. Para Parsons (2014) el concepto de movilidad para alcanzar un aprendizaje más fluido, adaptativo, colaborativo y exploratorio, promoviendo la porosidad entre la educación formal y la informal es fundamental. Sin embargo, se imponen barreras en tres niveles: (1) normativas educativas sobre la restricción del uso de los dispositivos móviles en el aula, (2) falta de conciencia por parte del alumnado de la utilidad educativa del teléfono móvil, y no meramente con fines lúdicos, y (3) desconocimiento de la potencialidad educativa de las aplicaciones móviles por parte de los docentes, considerándolos en ocasiones elementos disruptivos y de intromisión en el aula. Normativas, falta de conciencia del alumnado y desconocimiento de los docentes impiden, entre otros factores, que un medio universal en la actualidad como el teléfono móvil, acceda al aula como potencial herramienta de enseñanza y aprendizaje.

Sin embargo, esto no significa que no existieran inquietudes ni iniciativas de experimentación haciendo uso del teléfono móvil y otros dispositivos móviles en diversos contextos educativos con importantes dotaciones económicas para recursos materiales. La mayor parte se han desarrollado en Europa y Norteamérica. Se ha llevado a cabo una amplia recopilación de experiencias educativas de aprendizaje móvil en España y en el resto del mundo (Brazuelo y Gallego, 2011; Brazuelo, 2013) entre las que destacan, en España las basadas en proyectos piloto como: enlace, aprenda, PICAA, X-press2@'t, MW-Tell, e-Adventure, Español a la carta, Campusmovil.net. En otros países también se han puesto en marcha este tipo de iniciativas como las llevadas a cabo en América Latina (Ateneus Móvil, Eduinnova), Norteamérica (GeoHistorian, K-Nect, PBS Kids, Scott Newcomb, MENTIRA), Europa (WapEduc, MoLeNet, MOBILearn, Learning2Go, MyArtSpace, Math4Mobile), Asia y Oceanía (Mobilise, MILLEE) y África (m4Lit, MoMath, MobilEd).

Aunque los estudios sobre el uso educativo de los dispositivos móviles están teniendo una amplia difusión internacional (UNESCO, 2012, 2013; NMC, 2013, 2014), aún no son suficientes los dedicados específicamente al teléfono móvil a pesar de, la ya mencionada, masiva presencialidad social en el entono extraescolar.

Las categorías emergentes en el meta-análisis realizado por Alrasheedi \& Capretz (2015) para determinar los factores de éxito que afectan al aprendizaje móvil son: tecnología, apoyo a la gestión y estrategias de enseñanza y de aprendizaje. Por su parte, en un estudio Delphi llevado a cabo por Hsu, Ching \& Snelson (2014) los expertos han identificado como la principal prioridad de investigación en el campo del aprendizaje móvil: estrategias de enseñanza-aprendizaje: aprendizaje colaborativo, aprendizaje basado en juegos, aprendizaje basado en la investigación, simulación, difusión de contenidos enriquecidos y tutoría para un aprendizaje ubicuo.

Es por todo ello que, la presente investigación, ha dirigido su foco al cuerpo de docentes de Enseñanza Secundaria Obligatoria (ESO) y su relación, genérica y educativa, con el teléfono móvil. Los docentes deben ser los auténticos líderes educativos en la integración de las TIC en el aula. Su aceptación influye en las propias políticas

Los docentes ante la integración educativa del teléfono móvil en el aula. Francisco Brazuelo, Domingo José Gallego y María Luz Cacheiro. 
educativas, al menos, en el núcleo de sus centros educativos, de ahí el interés de abordar su uso por parte de los docentes de secundaria.

\section{Objetivos}

Ante un medio tecnológico como el teléfono móvil con un potencial educativo, didáctico y de gestión en los centros educativos, derivado de sus amplias posibilidades comunicativas, multimedia y de conexión a redes, se plantean cuestiones acerca de su infrautilización por parte de los docentes en el aula como son: ¿a qué se debería esta situación? ¿Ocurre por miedo? ¿Desconocimiento? ¿Infravaloración de estos medios? ¿Por razones económicas? ¿Cuáles son sus actitudes al respecto? ¿Qué uso hacen de este medio? ¿Creen que pueden tener posibilidades reales en el aula? ¿Cuáles serían?

Para intentar dar respuestas a estos cuestionamientos, los objetivos de la investigación planteados han sido:

- Analizar las actitudes de los docentes de la ESO respecto a la integración de la telefonía móvil como herramienta educativa.

- Evaluar los usos que realizan los docentes de la ESO de la telefonía móvil como recurso didáctico.

- Proponer posibilidades educativas del teléfono móvil desde la perspectiva de los propios docentes de la ESO.

\section{Metodología}

\section{Tipo de estudio}

El estudio llevado a cabo es de tipo exploratorio y descriptivo con un enfoque mixto, cuantitativo y cualitativo (León y Montero, 2004; Clares, 2006; Albert, 2007). La perspectiva metodológica utilizada se enmarca dentro del paradigma interpretativo que pretende la "comprensión de los fenómenos educativos a través del análisis de las percepciones e interpretaciones de los sujetos que intervienen en la acción educativa" (Colás y Buendía, 1998, p. 50). Con este diagnóstico se pretende llevar a cabo una búsqueda de información que sirva, a su vez, como punto de partida para futuras investigaciones de mayor concreción y propuestas de mejora.

\section{Muestra}

Los docentes que han participado en el estudio $(n=223)$ pertenecen a 30 Institutos de educación Secundaria de Las Palmas, siendo seleccionados por muestreo aleatorio estratificado (Colás y Buendía, 1998). Esta muestra supera el valor resultante de aplicar la fórmula de cálculo muestral $(\mathrm{n}=209)$ a una población de 900 docentes. Así mismo se ha entrevistado a docentes $(n=19)$ seleccionados con un tipo de muestreo no probabilístico por cuotas (Clares, 2006) en donde el investigador tenía facilidad de acceso a la muestra. Cabe señalar que un $32 \%$ de la muestra eran tutores, seguidos de un $30 \%$ que no ejercía ningún cargo de responsabilidad, limitando sus funciones principales a la acción docente directa, y un 26\% eran Jefes de Departamento. El resto $(11,6 \%)$ ejercían, principalmente, cargos directivos.

Los docentes ante la integración educativa del teléfono móvil en el aula. Francisco Brazuelo, Domingo José Gallego y María Luz Cacheiro. 
La caracterización de la muestra se presenta en función de las variables socioacadémicas analizadas (Brazuelo, 2013): edad, género, nivel académico, situación administrativa, antiguiedad docente y materia impartida:

- La media de edad de los docentes se haya comprendida entre los 36 y 51 años $(62,3 \%)$.

- Por géneros, las mujeres superan a los hombres $(52,9 \%$ y $47,1 \%$ respectivamente).

- El nivel académico general es de licenciado $(75,8 \%)$ y le siguen los diplomados con un $16,6 \%$ y el resto de titulaciones (un total de 7,6\%).

- La situación administrativa mayoritaria es la de funcionario (83\%).

- En cuanto a la antigüedad docente, el profesorado posee una amplia experiencia (el $83,3 \%$ tiene al menos 8 años) y tres franjas de reparten casi por igual el porcentaje de esta distribución: $24,2 \%$ entre 8 y 14 años; $24,2 \%$ entre 15 y 21 años; y 23,3\% entre 22 y 28 años).

- Por materias se distribuyen en Matemáticas (17,5\%), Ciencias Naturales (17\%), Lengua extranjera $(15,7 \%)$, Lengua Española (14,3\%) y Ciencias Sociales (20\%), que corresponden, generalmente, a los departamentos didácticos más numerosos en ESO. El resto (un 26,4\%) corresponden a materias como Tecnologías, Música, Educación Física, Educación Plástica y Visual y otras materias (Religión y Filosofía).

\section{Instrumentos}

El instrumento principal utilizado en la investigación ha sido el cuestionario, aplicado de forma presencial y virtual debido a la dispersión del territorio insular. Se ha completado la obtención de datos con entrevistas semiestructuradas a docentes.

El cuestionario ha sido previamente validado a través de la consulta a expertos y se ha aplicado a una prueba piloto obteniendo un alfa de Cronbach con valores de 0,543 (moderada) a 0.920 (muy alta) (Ruíz, 1995). El instrumento consta de 90 ítems estructurados en 10 dimensiones (anexo) incluyendo los aspectos más relevantes derivados del análisis de las fuentes documentales (estudios y experiencias). También se incluye un apartado de respuesta abierta para indicar las posibilidades educativas del teléfono móvil para cada una de las funcionalidades de la Dimensión J (Tabla 1).

Tabla 1

Dimensiones del cuestionario, tipos de preguntas, $n^{o}$ items, Alpha de Cronbach

\begin{tabular}{|l|l|l|l|}
\hline Dimensiones & $\mathbf{N}^{\circ}$ ítems & $\begin{array}{l}\text { Alpha de } \\
\text { Cronbach }\end{array}$ & Magnitud \\
\hline Datos generales del teléfono móvil. & 3 & .920 & Muy alta \\
\hline Hábitos de consume. & 12 & .543 & Moderada \\
\hline $\begin{array}{l}\text { Posibilidades multimedia, ofimáticas, conexión } \\
\text { inalámbrica e Internet. }\end{array}$ & 13 & .762 & Alta \\
\hline $\begin{array}{l}\text { Nivel de conocimientos previos en TIC. } \\
\text { Nivel general de conocimientos técnicos sobre telefonía } \\
\text { móvil. }\end{array}$ & 12 & .948 & Muy alta \\
\hline $\begin{array}{l}\text { Ambientes y usos del teléfono móvil en el centro educativo } \\
\text { y en el aula. }\end{array}$ & 6 & .822 & Muy alta \\
\hline Políticas educativas de prohibición de los teléfonos móviles & 5 & .610 & Alta \\
\hline
\end{tabular}

Los docentes ante la integración educativa del teléfono móvil en el aula. Francisco Brazuelo, Domingo José Gallego y María Luz Cacheiro. 


\begin{tabular}{|l|l|l|l|}
\hline $\begin{array}{l}\text { Motivos y actitudes a favor del uso educativo del teléfono } \\
\text { móvil. }\end{array}$ & 13 & .783 & Alta \\
\hline $\begin{array}{l}\text { Obstáculos y actitudes en contra de la incorporación } \\
\text { educativa del teléfono móvil. }\end{array}$ & 7 & .693 & Alta \\
\hline $\begin{array}{l}\text { Valoración del teléfono móvil como herramienta } \\
\text { educativa. }\end{array}$ & 16 & .896 & Muy alta \\
\hline
\end{tabular}

La entrevista ha sido individual, presencial y semiestructurada, permitiendo una interacción verbal entre entrevistador y entrevistado o informante (Rodríguez, Gil y García, 1996) para profundizar en algunas de las cuestiones del cuestionario. El perfil medio de la muestra del profesorado entrevistado es "profesora de entre 36 y 51 años, licenciada, funcionaria con destino definitivo y una antigüedad docente entre $\operatorname{los} 15$ y 21 años que trabaja en el sur de Gran Canaria e imparte lengua extranjera". Algunas de las cuestiones que se han planteado son: ¿Qué ventajas considera que puede tener el teléfono móvil como recurso educativo? ¿Cuáles cree que son los principales obstáculos para la incorporación del teléfono móvil como recurso educativo? ¿Qué usos del teléfono móvil ha realizado en el aula? ¿Conoce alguna experiencia al respecto?

\section{Resultados}

Se ha realizado un análisis univariado (frecuencias y porcentajes) y bivariado a través de pruebas no paramétricas (tablas de contingencia, chi-cuadrado de Pearson y coeficiente de asociación) (Gil, 2006). Así mismo se ha realizado una triangulación de los datos a partir de las respuestas abiertas del cuestionario y las entrevistas.

Del análisis descriptivo univariado se desprende que los docentes consideran que el teléfono móvil es un dispositivo al alcance del alumnado (89,3\%), con grandes capacidades multimedia $(74,9 \%)$ y facilitador de la comunicación con las familias $(80,7 \%)$.

El nivel de conocimientos técnicos es medio $(55,6 \%)$ y expresan su desconocimiento de experiencias de uso educativo $(93,3 \%)$, sin embargo, muestran un interés alto por conocer aplicaciones educativas del móvil (78,5\%). Así lo manifiestan cuando opinan que:

"El móvil es una tecnología que simplemente no utilizo por desconocimiento y este desconocimiento lleva a la desconfianza o a simplemente ni contemplarlo como algo útil a nivel educativo. Me resulta difícil concebirlo como útil en el aula, me plantea muchos interrogantes. Pero es sobre todo porque no tengo conocimiento de experiencias y usos en el aula." [P3_Inf. 7]

En cuanto a las Políticas educativas de prohibición de los teléfonos móviles (Dimensión G), un 78,5\% del profesorado se muestra a favor (Totalmente de acuerdo y De acuerdo) con la normativa de prohibición. Cuando se les pregunta durante la entrevista sobre esta prohibición, manifiestan que siempre o casi siempre $(72,4 \%)$ se trata de una medida preventiva, si bien uno de los encuestados opina que:

"El beneficio es mayor que la posible conflictividad. Y también hay que hacer un ejercicio de autoresponsabilizarse de sus propios materiales, educarles en ese sentido.”[P3_Inf. 3].

Los docentes ante la integración educativa del teléfono móvil en el aula. Francisco Brazuelo, Domingo José Gallego y María Luz Cacheiro. 
En la Dimensión H sobre Motivos y actitudes para el uso educativo del teléfono móvil, los resultados muestran una opinión mayoritariamente favorable hacia su uso educativo en los distintos ítems (Tabla 2).

Tabla 2.

Motivos y actitudes para el uso educativo del teléfono móvil

\begin{tabular}{|l|l|l|l|}
\hline $\begin{array}{l}\text { H. Motivos y actitudes para el uso educativo del } \\
\text { teléfono móvil }\end{array}$ & $\begin{array}{l}\text { Totalmente } \\
\text { de acuerdo } \\
\text { yeuerdo } \\
\text { ace }\end{array}$ & $\begin{array}{l}\text { Ni } \\
\text { acuerdo } \\
\text { en } \\
\text { desacuerdo }\end{array}$ & $\begin{array}{l}\text { En } \\
\text { desacuerdo y } \\
\text { Totalmente } \\
\text { en } \\
\text { desacuerdo }\end{array}$ \\
\hline $\begin{array}{l}\text { H1. El teléfono móvil es un dispositivo al alcance } \\
\text { de todo el alumnado. }\end{array}$ & $89,3 \%$ & $\%$ & $\%$ \\
\hline $\begin{array}{l}\text { H2. Posee grandes capacidades multimedia. } \\
\text { H3. Podemos consultar información a través de } \\
\text { Internet Móvil. }\end{array}$ & $74,9 \%$ & $19,7 \%$ & $4,9 \%$ \\
\hline $\begin{array}{l}\text { H4. El alumnado no necesita formación para su } \\
\text { utilización. }\end{array}$ & $52,1 \%$ & $12,1 \%$ & $3,4 \%$ \\
\hline $\begin{array}{l}\text { H5. Permite el aprendizaje en todo momento y } \\
\text { lugar. }\end{array}$ & $41,3 \%$ & $34,5 \%$ & $28,3 \%$ \\
\hline $\begin{array}{l}\text { H6. Facilitaría la comunicación con las familias. } \\
\text { H7. Favorece el feedback entre alumno y profesor. }\end{array}$ & $80,7 \%$ & $11,2 \%$ & $8,9 \%$ \\
\hline H18. Favorece el aprendizaje colaborativo. & $33,2 \%$ & $40,4 \%$ & $19,7 \%$ \\
\hline $\begin{array}{l}\text { H9. Puede abrir nuevas oportunidades de } \\
\text { aprendizaje. }\end{array}$ & $58,3 \%$ & $32,7 \%$ & $9 \%$ \\
\hline $\begin{array}{l}\text { H10. Un teléfono móvil es más económico que un } \\
\text { ordenador portátil. }\end{array}$ & $45,8 \%$ & $38,1 \%$ & $16,1 \%$ \\
\hline $\begin{array}{l}\text { H11. El teléfono móvil es motivante para el } \\
\text { alumnado. }\end{array}$ & $68,6 \%$ & $24,2 \%$ & $7,2 \%$ \\
\hline $\begin{array}{l}\text { H12. El teléfono móvil sería útil en la gestión del } \\
\text { centro. }\end{array}$ & $65,5 \%$ & $26,5 \%$ & $8,1 \%$ \\
\hline $\begin{array}{l}\text { H13. Estoy a favor de un uso educativo del teléfono } \\
\text { móvil pero solo fuera del aula. }\end{array}$ & $52,9 \%$ & $30,5 \%$ & $16,6 \%$ \\
\hline
\end{tabular}

Sin embargo, se constata un porcentaje también alto en la opción Indiferente cuando se les pregunta sobre las posibilidades para el feedback $(40,4 \%)$ y el aprendizaje colaborativo $(43,9 \%)$ del teléfono móvil.

En la Dimensión I sobre Obstáculos y actitudes en contra de la incorporación educativa del teléfono móvil, los resultados que se encuentran permiten constatar dudas como puede ser la interrupción producida por mensajes o llamadas en el aula (Tabla 3).

Los docentes ante la integración educativa del teléfono móvil en el aula. Francisco Brazuelo, Domingo José Gallego y María Luz Cacheiro. 
Tabla 3.

Obstáculos y actitudes en contra de la incorporación educativa del teléfono móvil

\begin{tabular}{|l|l|l|l|}
\hline $\begin{array}{l}\text { I. Obstáculos y actitudes en contra de la } \\
\text { incorporación educativa del teléfono móvil }\end{array}$ & $\begin{array}{l}\text { Totalmente } \\
\text { de acuerdo } \\
\text { y } \\
\text { acuerdo }\end{array}$ & $\begin{array}{l}\text { Ni } \\
\text { De } \\
\text { en } \\
\text { desaerdo ni } \\
\text { ni }\end{array}$ & $\begin{array}{l}\text { En } \\
\text { desacuerdo } \\
\text { Totalmente } \\
\text { en } \\
\text { desacuerdo }\end{array}$ \\
\hline $\begin{array}{l}\text { I1. Interrumpe las clases con llamadas o recepción } \\
\text { de SMS }\end{array}$ & $80,2 \%$ & $3,6 \%$ & $16,1 \%$ \\
\hline $\begin{array}{l}\text { I2. La pantalla de un teléfono móvil es demasiado } \\
\text { pequeña }\end{array}$ & $79,4 \%$ & $17,5 \%$ & $3,1 \%$ \\
\hline $\begin{array}{l}\text { I3. Temo que me hagan fotos o me graben con el } \\
\text { teléfono móvil sin mi consentimiento }\end{array}$ & $69,5 \%$ & $20,2 \%$ & $10,3 \%$ \\
\hline $\begin{array}{l}\text { I4. Considero el teléfono móvil un juguete y no una } \\
\text { herramienta de aprendizaje }\end{array}$ & $27,8 \%$ & $43,5 \%$ & $28,7 \%$ \\
\hline $\begin{array}{l}\text { I5. La ratio del alumnado impide su integración en } \\
\text { el aula }\end{array}$ & $60,5 \%$ & $26,5 \%$ & $13 \%$ \\
\hline I6. Los problemas de cobertura son frecuentes & $43,1 \%$ & $30,9 \%$ & $26 \%$ \\
\hline $\begin{array}{l}\text { I1. Interrumpe las clases con llamadas o recepción } \\
\text { de SMS }\end{array}$ & $80,2 \%$ & $3,6 \%$ & $16,1 \%$ \\
\hline
\end{tabular}

En la Dimensión J sobre la valoración del teléfono móvil como herramienta educativa las funcionalidades consideradas de mayor utilidad son las llamadas, los mensajes, la cámara de fotos y vídeo (Tabla 4).

Tabla 4.

Valoración del teléfono móvil como herramienta educativa

\begin{tabular}{|l|l|l|l|}
\hline $\begin{array}{l}\text { J. Valoración del teléfono } \\
\text { móvil como } \\
\text { educativa }\end{array}$ & Muy útil y Útil & Indiferente & Poco útil y Nada útil \\
\hline & $\%$ & $\%$ & $\%$ \\
\hline Llamadas & $72,2 \%$ & $15,2 \%$ & $12,5 \%$ \\
\hline SMS & $78 \%$ & $8,5 \%$ & $13,4 \%$ \\
\hline Internet & $67,7 \%$ & $23,3 \%$ & $9 \%$ \\
\hline GPS & $47,1 \%$ & $34,5 \%$ & $18,4 \%$ \\
\hline Messenger & $40,4 \%$ & $36,8 \%$ & $22,9 \%$ \\
\hline Email & $64,2 \%$ & $26,5 \%$ & $9,4 \%$ \\
\hline Calendario & $70,8 \%$ & $19,3 \%$ & $9,9 \%$ \\
\hline Reloj & $62,8 \%$ & $26,9 \%$ & $10,3 \%$ \\
\hline Cronómetro & $52,9 \%$ & $33,6 \%$ & $13,5 \%$ \\
\hline Calculadora & $70 \%$ & $21,1 \%$ & $9 \%$ \\
\hline
\end{tabular}

$\overline{\text { Los docentes ante la integración educativa del teléfono móvil en el aula. Francisco Brazuelo, }}$ Domingo José Gallego y María Luz Cacheiro. 


\begin{tabular}{|l|l|l|l|}
\hline Notas & $63,3 \%$ & $28,7 \%$ & $8,1 \%$ \\
\hline Grabadora de sonidos & $53,8 \%$ & $35 \%$ & $11,2 \%$ \\
\hline MP3 & $50,2 \%$ & $33,6 \%$ & $16,2 \%$ \\
\hline Radio & $42,2 \%$ & $39,9 \%$ & $18 \%$ \\
\hline Cámara de fotos & $67,3 \%$ & $19,3 \%$ & $13,5 \%$ \\
\hline Cámara de vídeo & $71,3 \%$ & $18,4 \%$ & $10,3 \%$ \\
\hline USB & & & \\
\hline Disco duro & $71,3 \%$ & $21,5 \%$ & $7,2 \%$ \\
\hline & $67,2 \%$ & $24,7 \%$ & $8,1 \%$ \\
\hline
\end{tabular}

En la pregunta abierta del cuestionario sobre las posibles aplicaciones educativas de las posibilidades de comunicación que ofrece el teléfono móvil se señalan las siguientes:

- Llamadas

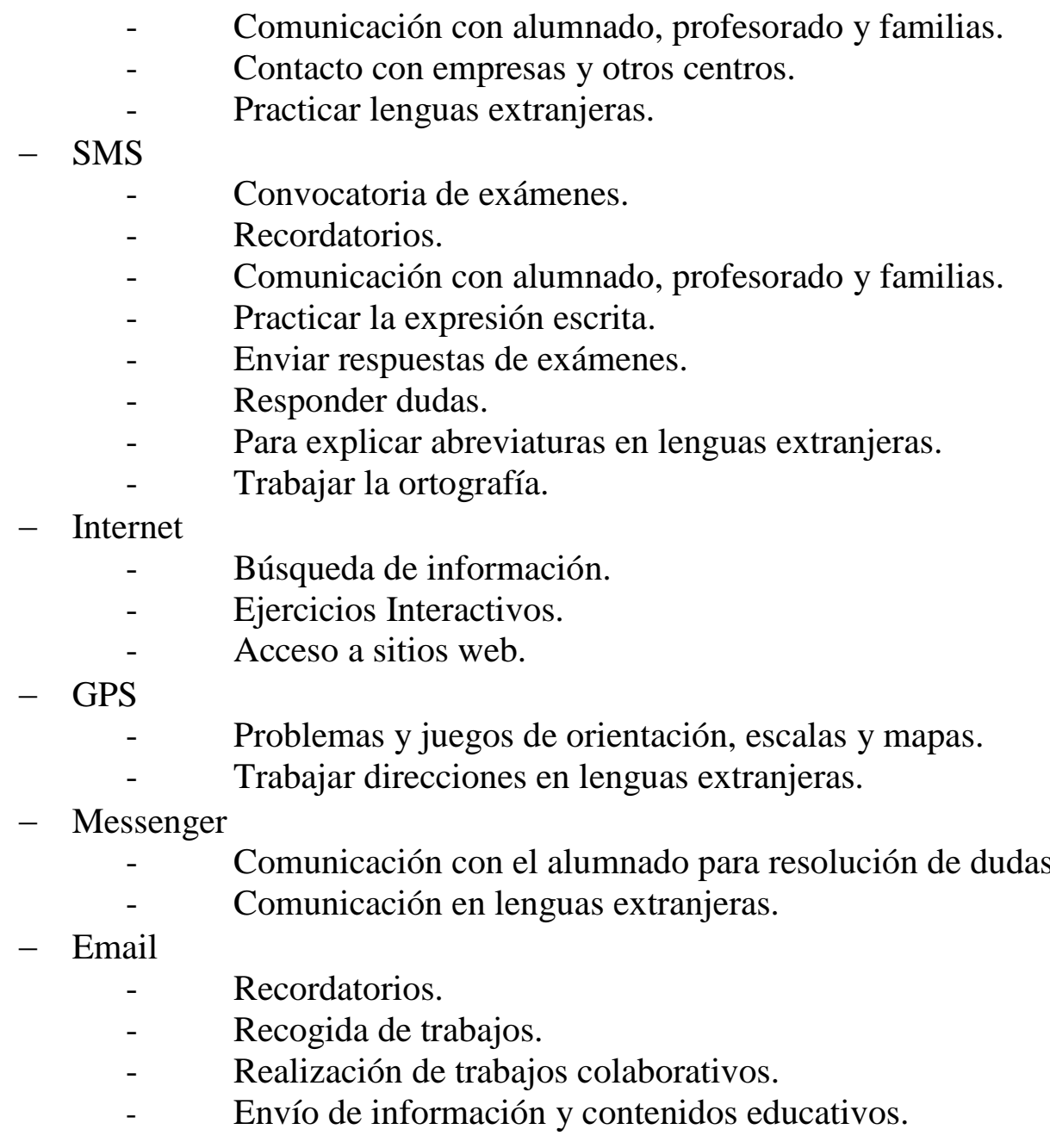

Al preguntarles sobre los usos del teléfono móvil en el aula los docentes entrevistados señalan:

Los docentes ante la integración educativa del teléfono móvil en el aula. Francisco Brazuelo, Domingo José Gallego y María Luz Cacheiro. 
"Una vez realizamos un trabajo que consistía en hacer entrevistas a gente mayor de la localidad para reflejar la forma en cómo vivían antes, la vida de nuestros abuelos en forma de relatos. Tenían un guion de preguntas y la mayor parte de los alumnos se ayudaron del móvil para grabar los relatos" [P7_Inf. 7].

Entre las ventajas señaladas por los docentes se encuentran:

"Creo que teléfono móvil puede ser una herramienta de aprendizaje, pero debe ser explorado como tal, más allá de su función de entretenimiento como chatear, jugar o escuchar música" [P3_Inf. 6]

"El alumnado lleva teléfonos de los últimos y pueden bajar lecturas, un montón de recursos. Y el alumno cada vez trae menos materiales al centro, por peso, por razones económicas, etc. Y el móvil puede ser un buen discurso en ese sentido, se halla muy extendido y todos o casi todos tienen y traen su móvil, aunque esté prohibido" [P4_Inf. 5]

Entre los principales obstáculos esgrimidos por los encuestados está el temor a que los alumnos hagan fotos o grabaciones con el móvil sin su consentimiento $(69,5 \%$, Totalmente de acuerdo y De acuerdo).

También se ha detectado en las entrevistas un alto porcentaje $(60 \%)$ de adjetivos negativos relacionados con las actitudes ante el teléfono móvil: conflictividad, temor, desconfianza, inadecuado, irresponsabilidad, recelo, rechazo, angustia, amenaza, resistencia, prejuicio.

Una de las dificultades señaladas en las entrevistas por parte de los docentes es la necesidad de formación en el uso educativo de los dispositivos móviles:

"Para mí la falta de formación es un obstáculo." [P6_Inf. 9]

"Siento verdadera angustia, ver cómo avanza la sociedad tecnológicamente hablando. "Necesitamos estar continuamente actualizados y está claro que no podemos dar la espalda a esta nueva tecnología que es el móvil.” [P3_Inf. 18]

A través del análisis bivariado, las variables socioacadémicas que se han tenido en cuenta son: la edad, el género, la antigüedad docente, la materia impartida, el grado de responsabilidad y el nivel de conocimientos TIC.

Con respecto a la edad, los docentes de menor edad (entre 36 y 50 años) tienen mayor dominio del teléfono móvil como herramienta para la búsqueda de información en Internet, mayor predisposición a otorgar oportunidades de aplicación didáctica de este medio y son menos restrictivos y más flexibles con su uso en el aula.

En cuanto al género, se ha detectado un mayor dominio técnico, predisposición para la aplicación en el aula y una visión más abierta por parte de los hombres con respecto a las mujeres. Además, los docentes con menor antigüedad docente, del área de ciencias y mayores niveles de conocimientos TIC, presentan actitudes y motivos más a favor que los docentes con menor antigüedad de otras áreas y menos versados en tecnología

Los docentes ante la integración educativa del teléfono móvil en el aula. Francisco Brazuelo, Domingo José Gallego y María Luz Cacheiro. 
educativa. Por el contrario, las variables sin influencia han sido: el nivel académico, la antiguiedad en el centro, la situación administrativa o el lugar del centro de trabajo.

\section{Resultados}

En relación a los objetivos establecidos en la investigación, se ha podido constatar, en el marco del estudio realizado, una radiografía sobre la situación del teléfono móvil en centros de secundaria de Las Palmas (Comunidad Autónoma de Canarias); mostrar como el teléfono móvil supone una potencial herramienta educativa; comprobar que, a pesar de su impacto social y prestaciones de variada índole, su uso se encuentra limitado en los centros educativos.

En este sentido, se ha detectado que las actitudes de los docentes son un factor favorecedor para su integración educativa. Se han evaluado los usos reales del teléfono móvil en la ESO y se han recopilado propuestas para su integración desde una perspectiva genérica y específica de cada materia.

Las experiencias o proyectos con tecnologías móviles, en el ámbito nacional español, son escasos y, especialmente, en la Enseñanza Secundaria Obligatoria, siendo uno de los mayores sectores sociales de consumo tecnológico móvil. Sí se encuentran buenas prácticas a nivel universitario y empresarial, así como en estudios llevados a cabo por organismos internacionales.

El estudio muestra el valor concedido por los docentes hacia un recurso, como es el teléfono móvil, en contextos educativos. Se considera que es un medio tecnológico dotado de numerosas y variadas funcionalidades multimedia, ofimáticas y de conexión a redes (superando incluso a un ordenador), que debería contar con un lugar entre las TIC aplicadas a educación.

Se ha señalado el impacto social de la telefonía móvil entre la comunidad educativa (docentes, alumnado y familias) y la necesidad de un vínculo permanente entre sociedad y escuela, con respecto al uso de las tecnologías. Esta sinergia ha de reflejarse en cambios normativos. Prohibir un medio connatural y cotidiano como es el teléfono móvil es negar sus posibilidades educativas, dejando de lado una potencial herramienta educativa al servicio del aprendizaje. En este sentido, se expresa uno de los docentes entrevistados:

"El teléfono móvil estaría prohibido, pero con matices" [P1_Inf. 5]

"Debería reglamentarse su uso para superar las barreras" [P2_Inf. 13]

"Para que tenga posibilidades se tienen que crear normas concretas de uso" [P10_Inf. 16]

"El beneficio es mayor que la posible conflictividad" [P3_Inf. 3]

Una de las claves, tal como reflejan los resultados de esta investigación, se encuentra en el desconocimiento de los docentes sobre la modalidad educativa del Aprendizaje Móvil

Los docentes ante la integración educativa del teléfono móvil en el aula. Francisco Brazuelo, Domingo José Gallego y María Luz Cacheiro. 
y de sus aplicaciones a nivel del aula. De ahí la demanda de una adecuada formación del profesorado que impulse su uso en su contexto educativo:

"Necesitamos formación en cómo usar el móvil" [P5_Inf. 17]

"Creo que nos estamos adentrando en un campo que nos queda muchísimo que descubrir” [P9_Inf. 6]

Como señala Zapata (2012) no se trata de evaluar el uso del dispositivo móvil, sino de las actividades en las que se ha incorporado para valorar su relevancia, pertinencia y ejecución en el transcurso de las mismas.

La vida ya es móvil y las instituciones educativas, en todos los niveles y ámbitos, deberían esforzarse por integrar y normalizar, y no por excluir sin más, estas potenciales herramientas educativas. En palabras de uno de los docentes:

El uso de las TIC debería ser algo normal en educación. Sin embargo, no es así y los prejuicios dominan a los docentes produciendo resistencias a la tecnología. Sería necesaria una mayor formación del profesorado en este sentido. Es muy importante contar con la tecnología para mejorar los aprendizajes. [P3_Inf.16]

Los jóvenes están viviendo en una sociedad digital, altamente tecnificada en la cual se encuentra omnipresente los dispositivos móviles. Esto ha generado nuevos contextos para la interacción donde el aprendizaje tiene lugar en todo momento y lugar gracias a la ubicuidad de estos medios.

Los resultados de este estudio suponen un punto de partida para la reflexión sobre las posibilidades de integración del teléfono móvil como recurso educativo. Sería interesante ampliar la muestra a alumnos y familias para detectar diferencias en las actitudes, usos y posibilidades de la telefonía móvil entre unos y otros.

\section{Propuestas para la integración del teléfono móvil para el aprendizaje}

Las tecnologías móviles han estado al margen del contexto escolar al ser consideradas como disruptivas o incitar a conductas inapropiadas. El desarrollo de actitudes del profesorado orientadas a fomentar la confianza y vencer las resistencias depende del conocimiento que se tenga de la tecnología en el ámbito educativo en el que se pretenda aplicar. Una adecuada integración de estos dispositivos como herramienta de enseñanza y aprendizaje exige, no solo de avances técnicos, sino propuestas de actuación (Brazuelo, 2013; UNESCO, 2013; Brazuelo y Gallego, 2011, 2014; Brazuelo, 2015). En este sentido se requiere:

- Difusión del uso educativo de las tecnologías móviles en el marco del Aprendizaje Móvil, mediante iniciativas que fomenten publicaciones que ejemplifiquen experiencias y proyectos que puedan ser emulados por otros.

- Creación de contenidos específicos y realizar adaptaciones metodológicas aprovechando las posibilidades y características de los dispositivos móviles.

$\overline{\text { Los docentes ante la integración educativa del teléfono móvil en el aula. Francisco Brazuelo, }}$ Domingo José Gallego y María Luz Cacheiro. 
- Formación del profesorado que enseñe a los docentes cómo integrar los dispositivos móviles en su quehacer diario con un enfoque práctico e integrador para mejorar los procesos de enseñanza.

- Incorporación de las tecnologías móviles en el currículum escolar como medios de apoyo normalizados.

- Cambio en las políticas educativas relacionadas con el Aprendizaje Móvil basadas en la reflexión y la acción de cambio iniciadas con la gradual eliminación de las limitaciones de las prohibiciones en los centros escolares.

Anexo.

Cuestionario sobre el teléfono móvil: actitudes, usos y posibilidades educativas

\begin{tabular}{|c|c|}
\hline Datos personales & \\
\hline DP.1. Edad & \\
\hline DP.2. Género & $\begin{array}{l}\text { ( ) } 1 . \text { Hombre } \\
\text { ( ) } 2 . \text { Mujer }\end{array}$ \\
\hline DP.3. Nivel académico máximo & $\begin{array}{l}\text { ( ) } 1 . \text { FP2 o equivalente } \\
\text { ( ) } 2 . \text { Diplomatura o equivalente } \\
\text { ( ) } 3 . \text { Licenciatura } \\
\text { ( ) } 4 . \text { Master o postgrado } \\
\text { ( ) } 5 . \text { Doctorado }\end{array}$ \\
\hline DP.4. ¿Cuál es su antigüedad en el centro? & \\
\hline DP.5. ¿Cuál es su antigüedad como docente? & \\
\hline $\begin{array}{l}\text { DP.6. ¿Cuál es su situación administrativa en su } \\
\text { centro de trabajo? }\end{array}$ & $\begin{array}{l}\text { ( ) } 1 . \text { Funcionario } \\
\text { ( ) } 2 . \text { Funcionario interino } \\
\text { ( ) } 3 . \text { Contratado laboral } \\
\text { ( ) } 4 . \text { Contratado laboral temporal } \\
\text { ( ) } 5 . \text { Otros: }\end{array}$ \\
\hline DP.7. Lugar de centro de trabajo & $\begin{array}{l}\text { ( ) } 1 . \text { Zona norte o noreste } \\
\text { ( ) } 2 . \text { Zona sur o sureste }\end{array}$ \\
\hline DP.8. ¿Qué materia principal imparte en el centro? & $\begin{array}{l}\text { ( ) } 1 . \text { Lengua española } \\
\text { ( ) } 2 . \text { Lengua extranjera } \\
\text { ( ) } 3 . \text { Matemáticas } \\
\text { ( ) } 4 . \text { Ciencias Sociales } \\
\text { ( ) } 5 . \text { Ciencias Naturales } \\
\text { ( ) } 6 . \text { Educación Plástica y Visual } \\
\text { ( ) } 7 . \text { Tecnologías } \\
\text { ( ) } 8 . \text { Educación física } \\
\text { ( ) } 9 . \text { Música } \\
\text { ( ) } 10 . \text { Otras materias: }\end{array}$ \\
\hline DP.9. ¿Ocupa algún cargo de responsabilidad? & $\begin{array}{l}\text { ( ) } 1 . \text { No } \\
\text { ( ) } 2 . \text { Director o Vicedirector } \\
\text { ( ) } 3 . \text { Jefe de Estudios } \\
\text { ( ) } 4 . \text { Secretario } \\
\text { ( ) } 5 . \text { Coordinador TIC } \\
\text { ( ) } 6 . \text { Jefe de Departamento } \\
\text { ( ) } 7 . \text { Tutor } \\
\text { ( ) } 8 . \text { Otros: }\end{array}$ \\
\hline Datos generales sobre el teléfono móvil & \\
\hline A1. ¿Qué marca tiene su móvil? & ( ) 1. Nokia \\
\hline
\end{tabular}

$\overline{\text { Los docentes ante la integración educativa del teléfono móvil en el aula. Francisco Brazuelo, }}$ Domingo José Gallego y María Luz Cacheiro. 


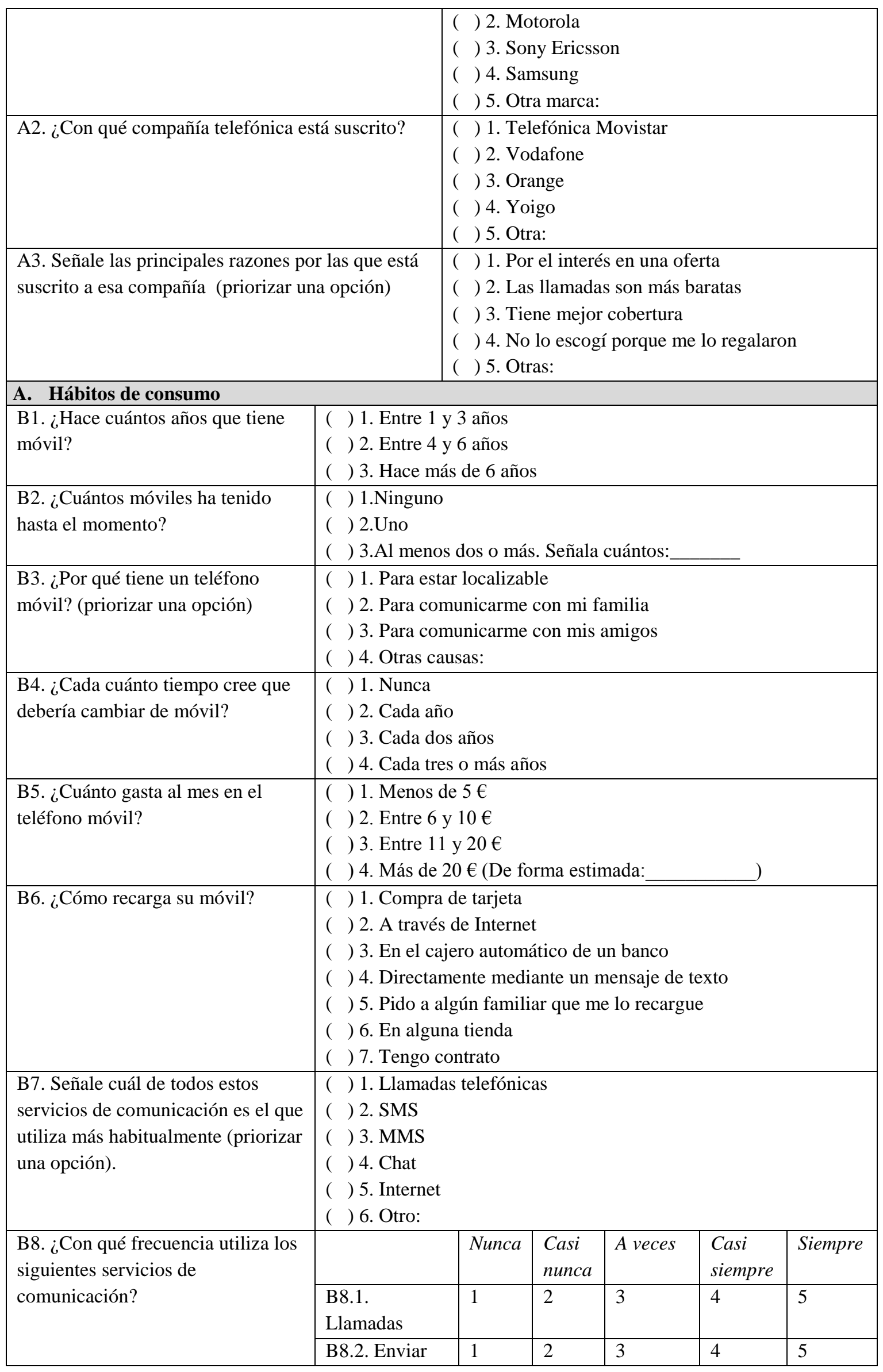

$\overline{\text { Los docentes ante la integración educativa del teléfono móvil en el aula. Francisco Brazuelo, }}$ Domingo José Gallego y María Luz Cacheiro. 


\begin{tabular}{|c|c|c|c|c|c|c|}
\hline & \multicolumn{6}{|l|}{ SMS } \\
\hline & $\begin{array}{l}\text { B8.3. Enviar } \\
\text { MMS }\end{array}$ & 1 & 2 & 3 & 4 & 5 \\
\hline & B8.4. Chat & 1 & 2 & 3 & \multicolumn{2}{|c|}{4} \\
\hline & B8.5. Internet & 1 & 2 & 3 & 4 & 5 \\
\hline $\begin{array}{l}\text { B9. ¿Cuántas llamadas realiza a la } \\
\text { semana? }\end{array}$ & \multicolumn{6}{|c|}{$\begin{array}{l}\text { ( ) } 1 . \text { Ninguna } \\
\text { ( ) } 2 \text {. Entre } 1 \text { y } 5 \\
\text { ( ) } 3 \text {. Entre } 6 \text { y } 10 \\
\text { ( ) } 4 \text {. Más de } 10 \text { (De forma estimada.__ }\end{array}$} \\
\hline $\begin{array}{l}\text { B10. ¿A quién suele llamar con el } \\
\text { móvil? (priorizar una opción) }\end{array}$ & \multicolumn{6}{|c|}{$\begin{array}{l}\text { ( ) } 1 . \text { Familia } \\
\text { ( ) } 2 . \text { Amigos } \\
\text { ( ) } 3 . \text { Información } \\
\text { ( ) } 4 . \text { Concursos } \\
\text { ( ) } 5 . \text { Emergencias } \\
\text { ( }) 6 . \text { Otros: }\end{array}$} \\
\hline $\begin{array}{l}\text { B11. ¿Cuántos SMS puede enviar } \\
\text { en una semana? }\end{array}$ & \multicolumn{6}{|c|}{$\begin{array}{l}\text { ( ) } 1 \text {. Ninguno } \\
\text { ( ) } 2 \text {. Entre } 1 \text { y } 5 \\
\text { ( ) } 3 \text {. Entre } 6 \text { y } 10 \\
\text { ( ) } 4 \text {. Más de } 10 \text { (De forma estimada: }\end{array}$} \\
\hline $\begin{array}{l}\text { B12. ¿A quién suele enviar SMS } \\
\text { con el móvil? (priorizar una } \\
\text { opción) }\end{array}$ & $\begin{array}{l}\text { ( ) } 1 . \text { Familia } \\
\text { ( ) } 2 \text {. Amigos } \\
\text { ( ) } 3 \text {. Informa } \\
\text { ( ) } 4 \text {. Concurs } \\
\text { ( ) } 5 \text {. Emerge } \\
\text { ( ) } 6 \text {. Otros: }\end{array}$ & & & & & \\
\hline \multicolumn{7}{|c|}{ B. Posibilidades multimedia, ofimáticas conexión inalámbrica e internet } \\
\hline \multirow{5}{*}{$\begin{array}{l}\text { C1. Indique qué posibilidades } \\
\text { multimedia tiene su móvil. }\end{array}$} & \multirow{2}{*}{\multicolumn{2}{|c|}{$\begin{array}{l}\text { C1.1. Cámara de } \\
\text { fotos }\end{array}$}} & Si & No & & No lo sé \\
\hline & & & 1 & 2 & & 3 \\
\hline & \multicolumn{2}{|c|}{$\begin{array}{l}\text { C1.2. Cámara de } \\
\text { vídeo }\end{array}$} & 1 & 2 & & 3 \\
\hline & \multicolumn{2}{|l|}{ C1.3. MP3 } & 1 & 2 & & 3 \\
\hline & \multicolumn{2}{|l|}{ C1.4. MP4 } & 1 & 2 & & 3 \\
\hline \multirow{4}{*}{$\begin{array}{l}\text { C2. ¿Qué formatos de imagen y } \\
\text { vídeo puede reproducir su móvil? }\end{array}$} & & Sí & No & & No lo sé \\
\hline & \multicolumn{2}{|l|}{ C2.1. WMA } & 1 & 2 & & 3 \\
\hline & \multicolumn{2}{|l|}{ C2.2. JPEG } & 1 & 2 & & 3 \\
\hline & \multicolumn{2}{|c|}{ C2.3.MPEG } & 1 & 2 & & 3 \\
\hline C3. ¿Tiene Bluetooth? & \multicolumn{6}{|c|}{ ( ) 1. Sí ( ) 2. No ( ) 3. No lo sé } \\
\hline C4. ¿Tiene conexión Wifi? & \multicolumn{6}{|c|}{ ( ) 1. Sí ( ) 2. No ( ) 3. No lo sé } \\
\hline $\begin{array}{l}\text { C5. ¿Envía o descarga mensajes } \\
\text { MMS? }\end{array}$ & \multicolumn{6}{|c|}{ ( ) 1. Sí ( ) 2. No ( ) 3. No lo sé } \\
\hline C6. ¿Tiene Internet en el móvil? & \multicolumn{6}{|c|}{ ( ) 1. Sí ( ) 2. No ( ) 3. No lo sé } \\
\hline C7. ¿Utiliza Internet con el móvil? & \multicolumn{6}{|c|}{ ( ) 1. Sí ( ) 2. No } \\
\hline $\begin{array}{l}\text { C8. En caso negativo, ¿por qué? } \\
\text { compañía (priorizar una opción) }\end{array}$ & $\begin{array}{l}\text { ( ) } 1 . \text { Porque } \\
\text { ( ) } 2 . \text { Porqu } \\
\text { ( ) } 3 \text {. Porqu }\end{array}$ & $\begin{array}{l}\text { s le } \\
\text { s ca } \\
\text { o lo }\end{array}$ & & & & \\
\hline
\end{tabular}

$\overline{\text { Los docentes ante la integración educativa del teléfono móvil en el aula. Francisco Brazuelo, }}$ Domingo José Gallego y María Luz Cacheiro. 


\begin{tabular}{|c|c|c|c|c|c|}
\hline \multirow{2}{*}{\begin{tabular}{|l} 
\\
C9. ¿Puede su teléfono móvil leer \\
documentos como archivos de texto \\
de Word, Excel o Powerpoint?
\end{tabular}} & \multicolumn{5}{|c|}{$\begin{array}{l}\text { ( ) 4. Para conectarme a Internet prefiero el ordenador. } \\
\text { ( ) } 5 . \text { Otras causas: }\end{array}$} \\
\hline & \multicolumn{5}{|c|}{ ( ) 1. Sí ( ) 2. No ( ) 3. No lo sé } \\
\hline \multirow{4}{*}{$\begin{array}{l}\text { C10. Indique si tiene alguno de estos } \\
\text { servicios u otros que no estén } \\
\text { señalados. }\end{array}$} & \multirow{2}{*}{\multicolumn{2}{|c|}{ C10.1. Radio }} & Sí & No & No lo sé \\
\hline & & & 1 & 2 & 3 \\
\hline & \multicolumn{2}{|c|}{ C10.2. GPS } & 1 & 2 & 3 \\
\hline & \multicolumn{2}{|c|}{$\begin{array}{l}\text { C10.3. Manos } \\
\text { libres }\end{array}$} & 1 & \begin{tabular}{c|c}
1 \\
\end{tabular} & 3 \\
\hline $\begin{array}{l}\text { C11. ¿Descarga aplicaciones como } \\
\text { juegos o melodías de Internet? }\end{array}$ & \multicolumn{5}{|c|}{$\begin{array}{l}\text { ( ) } 1 . \text { Nunca ( ) } 2 \text {. Casi nunca ( ) 3. A veces ( ) 4. Bastantes } \\
\text { veces ( ) } 5 \text {. Muchas veces }\end{array}$} \\
\hline $\begin{array}{l}\text { C12. De todo lo que te ofrece un } \\
\text { móvil, ¿qué es lo más utiliza? }\end{array}$ & \multicolumn{5}{|c|}{ Utilizo: } \\
\hline $\begin{array}{l}\text { C13. ¿Cuánta memoria tiene su } \\
\text { móvil? }\end{array}$ & 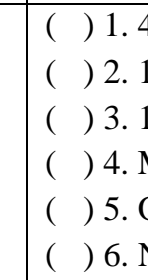 & $\begin{array}{l}\mathrm{IB} \\
\mathrm{MB} \\
\mathrm{B} \\
\text { de } \\
\text { lo sé }\end{array}$ & & & \\
\hline \multicolumn{6}{|c|}{ C. Nivel general de conocimientos previos en TIC } \\
\hline $\begin{array}{l}\text { D1. ¿Cómo definiría su nivel de } \\
\text { conocimientos TIC? }\end{array}$ & \multicolumn{5}{|c|}{$\begin{array}{l}\text { ( }) \text { 1. Bajo } \\
\text { ( ) } 2 . \text { Medio } \\
\text { ( ) } 3 . \text { Alto } \\
\text { ( }) \text { 4. Muy Alto }\end{array}$} \\
\hline $\begin{array}{l}\mathrm{D} 2 \cdot ¿ \text { Con cuánta frecuencia realiza } \\
\text { cursos de formación TIC? }\end{array}$ & \multicolumn{5}{|c|}{$\begin{array}{l}\text { ( ) } 1 . \text { Cada año } \\
\text { ( ) } 2 . \text { Cada dos años } \\
\text { ( ) } 3 . \text { Cada tres años o más } \\
\text { ( ) } 4 . \text { Nunca }\end{array}$} \\
\hline $\begin{array}{l}\text { D3. ¿Utiliza Internet como } \\
\text { herramienta educativa de forma } \\
\text { habitual? }\end{array}$ & \multicolumn{5}{|c|}{$\begin{array}{l}\text { ( ) } 1 . \text { Nunca } \\
\text { ( ) } 2 . \text { A veces } \\
\text { ( ) } 3 . \text { Casi siempre } \\
\text { ( }) \text { 4. Siempre }\end{array}$} \\
\hline \multicolumn{6}{|c|}{ D. Nivel general de conocimientos técnicos sobre telefonía móvil } \\
\hline & $\begin{array}{l}\text { No sé lo } \\
\text { que } \\
\text { significa }\end{array}$ & \multicolumn{2}{|c|}{$\begin{array}{l}\text { Sé lo que es } \\
\text { pero no sé } \\
\text { hacerlo }\end{array}$} & $\begin{array}{l}\text { Puedo hacerlo con } \\
\text { ayuda de alguien }\end{array}$ & $\begin{array}{l}\text { Puedo hacerlo } \\
\text { solo/a }\end{array}$ \\
\hline \multicolumn{6}{|l|}{ E1. Hacer una foto } \\
\hline \multicolumn{6}{|l|}{ E2. Grabar un vídeo } \\
\hline \multicolumn{6}{|l|}{ E3. Enviar un SMS } \\
\hline \multicolumn{6}{|l|}{$\begin{array}{l}\text { E4. Utilizar un buscador de } \\
\text { Internet }\end{array}$} \\
\hline \multicolumn{6}{|l|}{$\begin{array}{l}\text { E5. Crear un Powerpoint para } \\
\text { móviles }\end{array}$} \\
\hline \multicolumn{6}{|l|}{$\begin{array}{l}\text { E6. Diseñar una página web para } \\
\text { móviles }\end{array}$} \\
\hline \multicolumn{6}{|l|}{ E7. Crear un podcast } \\
\hline E8. Utilizar el chat & & & & & \\
\hline E9. Enviar un email por el & & & & & \\
\hline
\end{tabular}

$\overline{\text { Los docentes ante la integración educativa del teléfono móvil en el aula. Francisco Brazuelo, }}$ Domingo José Gallego y María Luz Cacheiro. 


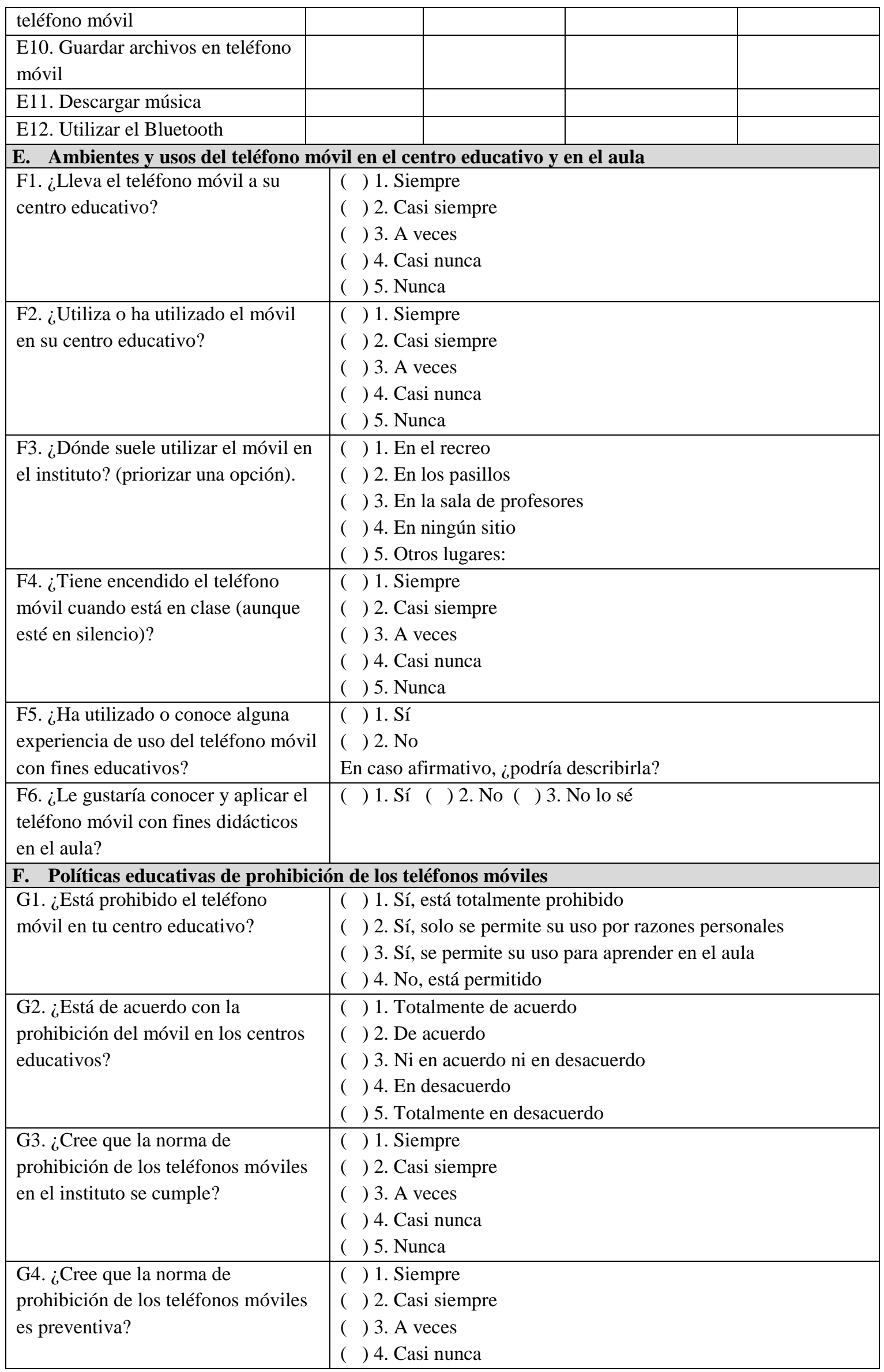

$\overline{\text { Los docentes ante la integración educativa del teléfono móvil en el aula. Francisco Brazuelo, }}$ Domingo José Gallego y María Luz Cacheiro. 


\begin{tabular}{|c|c|c|c|c|c|}
\hline & \multicolumn{5}{|l|}{ ( ) 5. Nunca } \\
\hline $\begin{array}{l}\text { G5. ¿Ha requisado alguna vez un } \\
\text { teléfono móvil? }\end{array}$ & \multicolumn{5}{|c|}{$\begin{array}{l}\text { ( ) } 2 . \text { No } \\
\text { En caso afirmativo, ¿cuántas veces lo ha hecho a lo largo de los } \\
\text { tres últimos años, de forma estimada? }\end{array}$} \\
\hline \multicolumn{6}{|c|}{ G. Motivos y actitudes favor del uso educativo del teléfono móvil } \\
\hline & $\begin{array}{l}\text { Totalmente } \\
\text { de acuerdo }\end{array}$ & $\begin{array}{l}\text { De } \\
\text { acuerdo }\end{array}$ & $\begin{array}{l}\text { Ni en } \\
\text { acuerdo ni } \\
\text { en } \\
\text { desacuerdo }\end{array}$ & $\begin{array}{l}\text { En } \\
\text { desacuerdo }\end{array}$ & $\begin{array}{l}\text { Totalmente } \\
\text { en } \\
\text { desacuerdo }\end{array}$ \\
\hline \multicolumn{6}{|l|}{$\begin{array}{l}\text { H1. El teléfono móvil es un } \\
\text { dispositivo al alcance de todo el } \\
\text { alumnado }\end{array}$} \\
\hline \multicolumn{6}{|l|}{$\begin{array}{l}\text { H2. Posee grandes capacidades } \\
\text { multimedia }\end{array}$} \\
\hline \multicolumn{6}{|l|}{$\begin{array}{l}\text { H3. Podemos consultar información } \\
\text { a través de Internet Móvil }\end{array}$} \\
\hline \multicolumn{6}{|l|}{$\begin{array}{l}\text { H4. El alumnado no necesita } \\
\text { formación para su utilización }\end{array}$} \\
\hline \multicolumn{6}{|l|}{$\begin{array}{l}\text { H5. Permite el aprendizaje en todo } \\
\text { momento y lugar }\end{array}$} \\
\hline \multicolumn{6}{|l|}{$\begin{array}{l}\text { H6. Facilitaría la comunicación con } \\
\text { las familias }\end{array}$} \\
\hline \multicolumn{6}{|l|}{$\begin{array}{l}\text { H7. Favorece el feedback entre } \\
\text { alumno y profesor }\end{array}$} \\
\hline \multicolumn{6}{|l|}{$\begin{array}{l}\text { H8. Favorece el aprendizaje } \\
\text { colaborativo }\end{array}$} \\
\hline \multicolumn{6}{|l|}{$\begin{array}{l}\text { H9. Puede abrir nuevas } \\
\text { oportunidades de aprendizaje }\end{array}$} \\
\hline \multicolumn{6}{|l|}{$\begin{array}{l}\text { H10. Un teléfono móvil es más } \\
\text { económico que un ordenador portátil }\end{array}$} \\
\hline \multicolumn{6}{|l|}{$\begin{array}{l}\text { H11. El teléfono móvil es motivante } \\
\text { para el alumnado }\end{array}$} \\
\hline \multicolumn{6}{|l|}{$\begin{array}{l}\text { H12. El teléfono móvil sería útil en } \\
\text { la gestión del centro }\end{array}$} \\
\hline \multicolumn{6}{|c|}{\begin{tabular}{l|l|l|l}
$\begin{array}{l}\text { H13. Estoy a favor de un uso } \\
\text { educativo del teléfono móvil pero }\end{array}$ & & & \\
solo fuera del aula & & & \\
\end{tabular}} \\
\hline \multicolumn{6}{|c|}{ H. Obstáculos y actitudes en contra de la incorporación educativa del teléfono móvil } \\
\hline & $\begin{array}{l}\text { Totalmente } \\
\text { de acuerdo }\end{array}$ & $\begin{array}{l}\text { De } \\
\text { acuerdo }\end{array}$ & $\begin{array}{l}\text { Ni en } \\
\text { acuerdo ni } \\
\text { en } \\
\text { desacuerdo }\end{array}$ & $\begin{array}{l}\text { En } \\
\text { desacuerdo }\end{array}$ & $\begin{array}{l}\text { Totalmente } \\
\text { en } \\
\text { desacuerdo }\end{array}$ \\
\hline \multicolumn{6}{|l|}{$\begin{array}{l}\text { I1. Interrumpe las clases con } \\
\text { llamadas o recepción de SMS }\end{array}$} \\
\hline \multicolumn{6}{|l|}{$\begin{array}{l}\text { I2. La pantalla de un teléfono móvil } \\
\text { es demasiado pequeña }\end{array}$} \\
\hline $\begin{array}{l}\text { I3. Temo que me hagan fotos o me } \\
\text { graben con el teléfono móvil sin mi } \\
\text { consentimiento }\end{array}$ & & & & & \\
\hline
\end{tabular}

$\overline{\text { Los docentes ante la integración educativa del teléfono móvil en el aula. Francisco Brazuelo, }}$ Domingo José Gallego y María Luz Cacheiro. 


\begin{tabular}{|c|c|c|c|c|c|c|}
\hline \multicolumn{3}{|c|}{$\begin{array}{l}\text { I4. Considero el teléfono móvil un } \\
\text { juguete y no una herramienta de } \\
\text { aprendizaje }\end{array}$} & & & & \\
\hline \multicolumn{7}{|c|}{$\begin{array}{l}\text { I5. La ratio del alumnado impide su } \\
\text { integración en el aula }\end{array}$} \\
\hline \multicolumn{7}{|c|}{$\begin{array}{l}\text { I6. Los problemas de cobertura son } \\
\text { frecuentes }\end{array}$} \\
\hline \multicolumn{7}{|c|}{$\begin{array}{l}\text { I7. Sería costoso económicamente } \\
\text { para el alumnado }\end{array}$} \\
\hline \multicolumn{7}{|c|}{ I. Valoración del teléfono móvil como herramienta educativa } \\
\hline \multicolumn{2}{|c|}{ Funcionalidad } & \multirow{2}{*}{ Muy útil } & \multirow[t]{2}{*}{ Útil } & \multirow{2}{*}{ Indiferente } & \multirow[t]{2}{*}{ Poco útil } & \multirow[t]{2}{*}{ Nada útil } \\
\hline $\mathrm{J} 1$ & Llamadas & & & & & \\
\hline $\mathrm{J} 2$ & SMS & & & & & \\
\hline $\mathrm{J} 3$ & Internet & & & & & \\
\hline $\mathrm{J} 4$ & GPS & & & & & \\
\hline J5 & Messenger & & & & & \\
\hline \multirow[t]{2}{*}{ J6 } & Email & & & & & \\
\hline & Organización & & & & & \\
\hline $\mathrm{J} 7$ & Calendario & & & & & \\
\hline J8 & Reloj & & & & & \\
\hline J9 & Cronómetro & & & & & \\
\hline $\mathrm{J} 10$ & Calculadora & & & & & \\
\hline \multirow[t]{2}{*}{$\mathrm{J} 11$} & Notas & & & & & \\
\hline & Sonidos & & & & & \\
\hline $\mathrm{J} 12$ & $\begin{array}{l}\text { Grabadora de } \\
\text { sonidos }\end{array}$ & & & & & \\
\hline $\mathrm{J} 13$ & MP3 & & & & & \\
\hline \multirow[t]{2}{*}{$\mathrm{J} 14$} & Radio & & & & & \\
\hline & $\begin{array}{l}\text { Fotos y } \\
\text { vídeos }\end{array}$ & & & & & \\
\hline $\mathrm{J} 15$ & $\begin{array}{l}\text { Cámara de } \\
\text { fotos }\end{array}$ & & & & & \\
\hline \multirow[t]{2}{*}{$\mathrm{J} 16$} & $\begin{array}{l}\text { Cámara de } \\
\text { vídeo }\end{array}$ & & & & & \\
\hline & $\begin{array}{l}\text { Memoria y } \\
\text { conexión }\end{array}$ & & & & & \\
\hline $\mathrm{J} 17$ & USB & & & & & \\
\hline $\mathrm{J} 18$ & Disco duro & & & & & \\
\hline \multicolumn{7}{|c|}{ J. $\quad$ Posibilidades educativas del teléfono móvil desde la materia que imparte } \\
\hline \multicolumn{2}{|c|}{ Funcionalidad } & \multicolumn{5}{|c|}{ ¿Cómo podría utilizar esta funcionalidad para enseñar y aprender? } \\
\hline K1 & Llamadas & & & & & \\
\hline $\mathrm{K} 2$ & SMS & & & & & \\
\hline K3 & Internet & & & & & \\
\hline K4 & GPS & & & & & \\
\hline K5 & Messenger & & & & & \\
\hline K6 & Email & & & & & \\
\hline & Organización & & & & & \\
\hline K7 & Calendario & & & & & \\
\hline K8 & Reloj & & & & & \\
\hline K9 & Cronómetro & & & & & \\
\hline
\end{tabular}

$\overline{\text { Los docentes ante la integración educativa del teléfono móvil en el aula. Francisco Brazuelo, }}$ Domingo José Gallego y María Luz Cacheiro. 


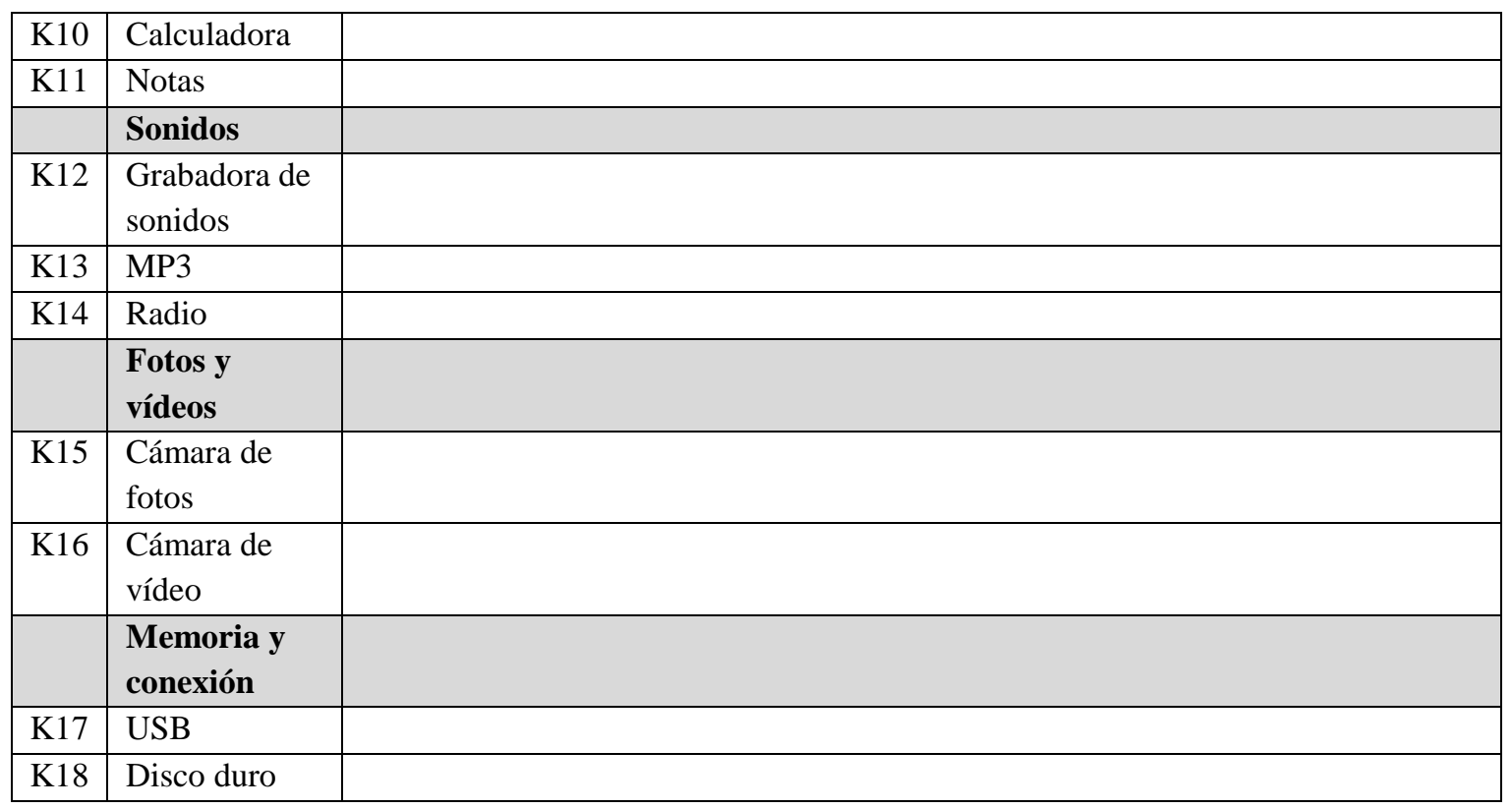

Presentación del artículo: 9 de marzo de 2016

Fecha de aprobación: 26 de junio de 2016

Fecha de publicación: 30 de enero de 2017

Brazuelo, F., Gallego, D.J., y Cacheiro, M.L. (2017). Los docentes ante la integración educativa del teléfono móvil en el aula. RED. Revista de Educación a Distancia, 52. Consultado el (dd/mm/aaaa) en http://www.um.es/ead/red/52

\section{Referencias bibliográficas}

Albert, M.J. (2007). La investigación educativa. Madrid: McGraw Hill.

Alrasheedi, M. \& Capretz, L.F. (2015). Determination of Critical Success Factors Affecting Mobile Learning: A Meta-Analysis Approach. TOJET, The Turkish Online Journal of Educational Technology, 14(2), 41-51.

Attewell, J., Savill-Smith, C. y Douch, R. (2009). The impact of mobile learning. Recuperado de https://crm.lsnlearning.org.uk/user/order.aspx ?code=090068

Bates, A.W. (2015). Teaching in a digital age. Recuperado de https://opentextbc.ca/teachinginadigitalage/

Brazuelo, F. (2013). El teléfono móvil: actitudes, usos y posibilidades educativas. Tesis doctoral. Universidad Nacional de Educación a Distancia. Madrid, España.

Brazuelo, F. (2015). Recursos móviles y realidad aumentada. En M.L. Cacheiro, C. Sánchez y J.M. González (coords.), Recursos tecnológicos en contextos educativos (pp. 399-432). Madrid: UNED.

$\overline{\text { Los docentes ante la integración educativa del teléfono móvil en el aula. Francisco Brazuelo, }}$ Domingo José Gallego y María Luz Cacheiro. 
Brazuelo, F. y Cacheiro, M.L. (2015). Estudio de adaptabilidad para dispositivos móviles en plataformas MOOC. RED, Revista de Educación a Distancia, 47(1), 113. DOI: http://dx.doi.org/10.6018/red/47/1

Brazuelo, F. y Gallego, D. (2011). Mobile Learning: los dispositivos móviles como recurso educativo. Sevilla: MAD.

Brazuelo, F. y Gallego, D. (2014). Estado del Mobile Learning en España. Educar em Revista, 4, 99-128. Recuperado de http://ojs.c3sl.ufpr.br/ojs/index.php/educar/article/view/38646/24340. DOI: 10.1590/0104-4060.38646.

Clares, J. (2006). Informática Aplicada a la Investigación Educativa. Sevilla: Digital Atres.

Colás, M. y Buendía, L. (1998). Investigación Educativa. Sevilla: Alfar.

CONECTA (2012). Séptimo observatorio de tendencias Nokia. Recuperado de http://www.slideshare.net/conectarc/7-observatorio-de-tendencias-nokia-los-jveneslos-mviles-y-la-tecnologa

Corbell, J. (2007). Are you ready for mobile learning? EDUCAUSE Quarterly, 30(2), 51-58.

Dykes, G. y Renfrew, H. (2012). Mobile Learning for Teachers in Europe: Exploring the Potential of Mobile Technologies to Support Teachers and Improve Practice. París: UNESCO.

Gil, J.A. (2006). Estadística e informática (SPSS) en la investigación descriptiva e inferencial. Madrid: UNED

Hsu, Y-Ch., Ching, Y-H. \& Snelson, Ch. (2014). Research priorities in mobile learning: an international Dekphi study. CJLT, Canadian Journal of Learning and Technology, 40(2), 1-22.

International Telecommunication Union (2015). ICT Facts an Figures. Recuperado de https://www.itu.int/en/ITU-D/Statistics/Documents/facts/ICTFactsFigures2015.pdf

Kadirire, J. (2007). Instant Messaging for Creating Interactive and Collaborative mLearning Environments. International Review of Research in Open and Distance Learning, 8, 1-14.

León, O. y Montero, I. (2004). Métodos de investigación en Psicología y Educación. Madrid: McGraw-Hill.

NMC (2013). Horizon Report. K-12 Edition. Recuperado de http://www.nmc.org/pdf/2013-horizon-report-k12.pdf

NMC (2014). NMC Horizon Report Europe. 2014 Schools Edition. Recuperado de http://cdn.nmc.org/media/2014-nmc-horizon-report-EU-EN.pdf

Los docentes ante la integración educativa del teléfono móvil en el aula. Francisco Brazuelo, Domingo José Gallego y María Luz Cacheiro. 
ONTSI (2016). Observatorio Nacional de las Telecomunicaciones y de la Sociedad de la Información. Madrid, España: Ministerio de Industria, Energía y Turismo. Recuperado de http://www.ontsi.red.es/ontsi/es/indicador/evoluci\%C3\%B3n-deln\%C3\%BAmero-de-clientes-de-telefon\%C3\%ADa-m\%C3\%B3vil-enespa\%C3\%B1a

Parsons, D. (2014). The Future of Mobile Learning and Implications for Education and Training. En M. Ally y A. Tsinakos (eds.), Increasing Access Through Mobile Learning (pp. 217-229). Commonwealth of Learning y Athabasca University, Vancouver, 2014. Recuperado de http://www.col.org/resources/increasing-accessthrough-mobile-learning-0

Rodríguez, G., Gil, J. y García, E. (1996). Metodología de la investigación cualitativa. Málaga: Aljibe.

Ruíz, J. (1995). El Estudio de Casos. Fundamentos y Metodología. Madrid: UNED.

Sánchez, J. C., Olmos, S., \& García, F. J. (2016). Informal Tools in Formal Contexts: Development of a Model to Assess the Acceptance of Mobile Technologies among Teachers. Computers in Human Behavior, 55, 519-528. doi:http://dx.doi.org/10.1016/j.chb.2015.07.002

Sharples, M. (2010). Exploring Theories and Practices in Mobile Learning. China Educational Technology, 3, 1-7.

Traxler, J. (2009). Learning in the Mobile Age. Recuperado de http://wlv.academia.edu/JohnTraxler/Papers/83099/Learning_in_a_Mobile_Age

UNESCO (2012). Aprendizaje móvil para docentes: Temas globales. París: UNESCO. Recuperado de http://unesdoc.unesco.org/images/0021/002164/216452s.pdf

UNESCO (2013). El futuro del aprendizaje móvil: implicaciones para la planificación y la formulación de políticas. París: UNESCO. Recuperado de http://unesdoc.unesco.org/images/0021/002196/219637s.pdf

Woodill, G. (2010). The Mobile Learning Edge. New York: McGraw-Hill.

Zapata, M. (2012). Calidad en entornos ubicuos de aprendizaje. RED. Revista de Educación a Distancia, 31, 1-12. Recuperado de http://www.um.es/ead/red/31/zapata_ros.pdf 